\title{
Study on the Design of Incentive Mechanism for Tourism Professional Executive
}

\author{
Wang Yuanhao \\ Ningbo Institute of Technology of Zhejiang University \\ Ningbo, China \\ nitwyh@126.com
}

\author{
Li Shaoying \\ Ningbo Institute of Technology of Zhejiang University \\ Ningbo, China \\ 1sy_cici@126.com
}

\begin{abstract}
Currently, in the increasingly fierce market competition environment, the shortage of excellent professional executive seriously restricted the development of tourism. Therefore, how to establish a scientific and reasonable professional executive incentive and restraint mechanisms, and how to maximize its management expertise has become a major problem that must be solved for further development of the tourism industry. In this paper, the author firstly analyzes the existing problems and main reasons of the incentive mechanism of tourism professional executive, and then puts forward the scientific and reasonable incentive and restraint mechanism of tourism professional executive, which combines both material and spiritual incentives, internal supervision and external restraint, so as to provide some ideas for the promotion of the rapid development of the tourism industry.
\end{abstract}

Keywords-Tourism; professional executive; incentive mechanism

\section{INTRODUCTION}

At present, in the management or economics, professional executive do not have a complete and precise definition. The French economist Zaire first proposed the "professional executive" concept. He defines a professional executive as a person who transfers economic resources from areas of low productivity to less productive areas to areas of greater productivity and productivity. John Peter Drucker defines a professional executive as someone who can initiate change, design change, and organizational change. The Chandler defines it as the following description: A professional executive is a person who takes management as his life-long occupation and has become a responsible businessman.

In summary, the author of this article defines the professional executive as a person who can make full use of all the resources of enterprises and individuals to realize the management of enterprises by the impact of multi-dimensional contract specific management groups. And the author of this article defines the tourism professional executive as a person who is familiar with the hotels, travel agencies, scenic spots management, and can make a full use of all the resources of tourism in order to achieve business objectives and is a salaried employee in a managerial capacity. In general, the tourism professional executives are tourism enterprises as chief executive officer, general executive, senior department executive and other staff positions. In the tourism industry, professional executive are the main operators and plays a very important role in the business decision-making and resource allocation. Therefore, we should build a scientific and reasonable incentive mechanism for modern professional executive, which is great significance to the development and growth of tourism enterprises.

Many domestic and foreign experts and scholars have studied the related problems of tourism professional executive For example: Shen Bo (2008) described the development of China's tourism professional executive mechanism and suggested that tourism professional executive own competitive strength needs to be further strengthened in the face of strong foreign tourism enterprises through the analysis of the present situation of tourism professional executive in China. Gu Yufen (2007) made the following points: Currently, the formation of a set of beneficial to the hotel industry professional executive training, market, incentive, restraint, security and self-improvement mechanism has become a major issue in the development of China's hotel industry. This is immeasurable value and role for the promotion of the rapid development of the modern hotel industry.

\section{The Present Situation AND Problems of the INCENTIVE MECHANISM OF TOURISM PROFESSIONAL EXECUTIVE}

Incentive mechanism refers to the sum of the structure, mode, relation and evolution law of the interaction and mutual restraint between the incentive subject system and the incentive object. Incentive mechanism is the enterprise will be lofty ideals into specific facts of the connection means. A certain incentive mechanism will "automatically" lead to stimulate the object of a certain behavior, showing certain regularity. Once the incentive mechanism is formed, it can continue to effectively play a role. However, there are some problems in the incentive mechanism of modern executive in tourism:

\section{A. The incentive mechanism is single}

Tourism enterprises would establish a set of incentive system in the process of stimulating professional executive, but in the implementation of the incentive system, they usually find that the incentive effect is not satisfactory; It mainly because of its incentive mechanism is single. Specifically, the performance is: First, the incentive system is fixed. In many enterprises, there is a misunderstanding that as long as the incentive system is established, it would have incentive effect. However, it turns out that once the incentive system is static, employees will be treated as a normal 
incentive, losing the original irritation. Incentive is a dynamic process, which needs to adjust the incentive plan as far as possible, so as to ensure the validity of incentive. Second, the incentive mechanism is not personalized enough. Each enterprise's incentive mechanism will not exactly the same, Its industry background, development stage, development strategy, corporate culture are not the same, Therefore, enterprises must design their own incentives according to their own mechanism. It is particularly important for an enterprise having Individuation design of incentive mechanism of professional executive.

\section{B. Pay structure is unreasonable}

The pay structure is not reasonable enough by the lack of long-term incentives. The tourism enterprises generally take the form of "wage plus bonus" or "annual salary system" for the payment of tourism professional executive. According to a survey of senior executives in Chinese listed companies, nearly half of the CEO do not own shares in the companies they run, and the top executive of the companies accounted for $85 \%$ of their total compensation.

\section{Insufficient retirement incentives}

The retirement policy of professional executive and the general staff is the same, Pensions are based on the average wage, which makes them on their retirement life doubts, and large extent affects their business mentality. Thus, when they are dominant in the enterprise, they will actively pursue on-the-job consumption, gray income or even black income; as the power approaching retirement and associated with hidden income is about to be lost, some people tend to desperate for a big profit.

\section{The incentive structure is biased}

The income of professional executive is restricted by all kinds of requirements, at a relatively low level, the professional executive are not satisfied with their own remuneration. However, part of the operators of gray income, or even illegal income, constitute their main source of income.

\section{E. Trust incentives is inadequate}

Tourism business owners can't fully authorized to the professional executive, and the professional executive feel that they can't be trusted in company. As a result of the crisis of trust between boss and professional executive, it will inevitably cause disputes between them in terms of authority, while the typical executive "control of incomplete" phenomenon is a common phenomenon that the owner strengthens the enterprise control.

\section{DESIGN OF INCENTIVE MECHANISM FOR TOURISM PROFESSIONAL EXECUTIVE}

In order to achieve competitive advantage and achieve sustainable development in the competitive market environment, it is necessary for the tourism enterprises to solve the problem of the distribution of benefits between the tourism enterprise owners and the professional executive. Therefore, it is necessary to establish scientific and reasonable incentive restraints for professional executive Mechanism (shown in Fig. 1), in order to promote professional executive to maximize their own initiative and creativity, and promote the steady and rapid increase of human capital, so as to promote the tourism business performance.

\section{A. The establishment of an effective material incentive mechanism for professional executive}

The tourism enterprises establish EVA-based economic value-added incentive mechanism for the professional executive; EVA is the net operating profit after tax minus the cost of all the value of capital, which is an important indicator of company performance measurement. EVA is positive, it shows that the company's operating income after deducting all costs and expenses still have surplus, this part of the residual income ownership belongs to the enterprise owner or shareholder. EVA-based incentive compensation model compared with the traditional incentive compensation model is very scientific and reasonable; the specific performance is as follows:

\section{1) It helps to maintain the sustainable development of tourism capacity.}

The incentive compensation contract of professional executive is based on the wisdom and effort of professional executive to increase the value of enterprises. EVA-based incentives can more accurately reflect the efforts of professional executive to increase the value of the enterprise competitive advantage, so as to effectively control operational risks and enhance the capacity of sustainable development.

2) It helps to reduce the information asymmetry caused by professional executive of short-term operating behavior.

As the professional executive pay the labor mainly for business decision-making, and this behavioral information has the effect of deferred income. The incentive compensation mechanism based on the EVA can largely avoid the short-term behavior of professional executive, which can ensure that the owner's interests of tourism enterprises are maximized.

\section{3) It helps to reduce agent risk.}

The incentive compensation mechanism based on EVA can unify the goal of executive and enterprise owner, and make the professional executive pay more attention to the capital structure and risk control of the enterprise, so as to effectively reduce the agency risk.

\section{B. Establish an effective spiritual incentive mechanism}

According to Maslow's hierarchy of needs theory, professional executive with high human capital stock will naturally pursue the satisfaction of higher level needs such as respect and self-fulfillment after the basic material needs are satisfied. According to the higher level of professional executive' spirit needs, the enterprise has designed a series of spiritual incentives for professional executive, including job incentives, honor incentives, emotional incentives, etc. 


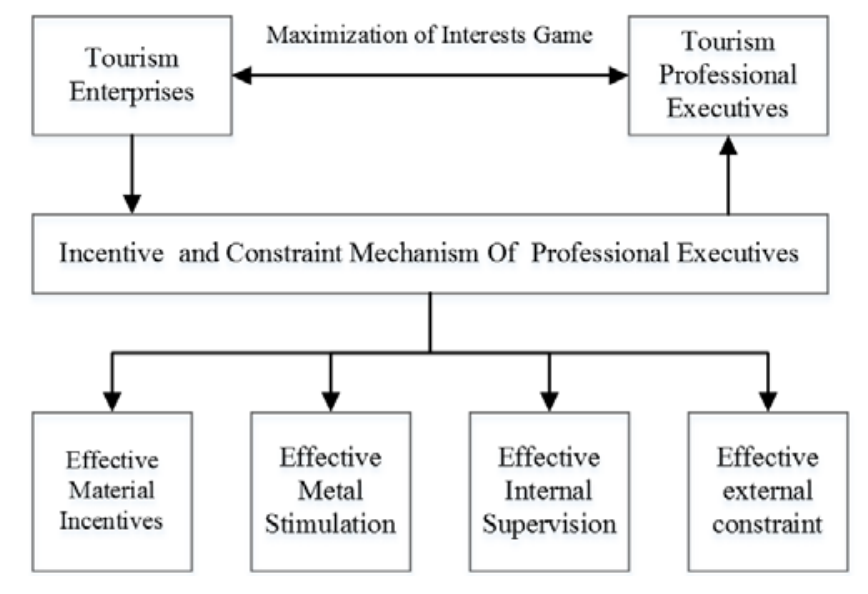

Fig. 1.Incentive constraint diagram

However, because the spirit of the art of motivation is strong and its role is really hidden, so the spirit of motivation is often not implemented after a period of time. After the professional executives were engaged in business management in the tourism enterprise, they received a series of material incentives from business owners. Therefore, enterprises' owner should focus on the establishment the spirit incentive mechanism of the work itself, so as to promote the effective performance of professional executive.

\section{Establish an effective internal control mechanism}

\section{1) The establishment of supervision of the organization}

Whether the internal organs of tourism enterprises 5 can play a supervisory role on professional executive, the key is whether the shareholders' meeting, the board of directors, the board of supervisors, management can form a sound internal checks and balances mechanism. First of all, we should change ideas, set up a professional executive responsible for the board of directors, and consciously accept the board of supervisors; secondly, we should give full play to the core role of the board of directors in corporate governance structure, design the reasonable structure of the board of directors, in addition, the internal directors must have a certain percentage of independent outside directors; lastly, we must strengthen the position of the board of directors and board of supervisors, we should evaluate for the performance of professional executive, The board of directors would coordinate the differences between the professional executive and the tourism enterprise' owner on the business development strategy.

2) Set up a labor contract and the rules and regulations of the supervision mechanism

In China where the current legal system is not perfect, the tourism enterprises mainly make full use of the contract's normative restraint to the executive, and sign the contract protected by law with the executive as perfect as possible. For professional executive, the contract make it clear on their responsibilities, rights and interests, in particular, When the professional executive leave the original employed enterprises, the contract strictly provides the responsibility of the professional executive about the business of trade secrets, patents and other aspects of technology.
Enterprise rules and regulations should make the appropriate provisions on the interests of various stakeholders within the enterprise rights and interests and their behavior, including the responsibilities, rights, interests of professional executive and their behavior.

\section{3) The establishment of job performance file monitoring mechanism}

After obtaining the necessary authorization from the professional executive, the tourism enterprises should establish a complete professional performance management system for professional executive. The specific objectives and tasks of tourism enterprises are inseparable from the actual participation of professional executive, professional executive involved in any work process, their work results, the level of efficiency will be recorded into the personal work performance files. The enterprise evaluates the ability and morality of professional executive from both positive and negative aspects; this formed a professional executive's reputation. The professional executive's reputation will directly affect the evaluation of the human capital value. Therefore, the professional executive will consider the "future employ ability" and be responsible for his own work.

\section{Construct an effective external constraint mechanism}

Market competition for professional executive of tourism enterprises, it is a strong pressure to inspire them to mobilize their full potential and talent, motivate them to fight for the survival and development opportunities. The inherent law of market competition also makes them participate in the competition by market factors. The market should be more responsible for coordinating the contradiction between the owner and operator objectives, and not by the government to play this role. We should strengthen the establishment and improvement of the market of the professional executive, so that the market of professional executive can promote the effective flow of professional executive, at the same time, and restrain professional executive in the flow of non-standard behavior or even illegal behavior. In addition, a legal system should be set up to protect market order, protect property rights and punish unfair competition, so as to provide a fair, stable and efficient external environment for the benign game between tourism enterprises and professional executive.

\section{SUMMARY}

From the research of this paper, we should insist on the motivating mechanism of the professional executive of tourism enterprises, we must insist on the salary incentive of the professional executive, and we should pay more attention to the motivating mechanism of the professional executive of the tourism enterprises, Adhere to the professional executive of human capital to participate in the distribution of residual rights and interests of enterprises, and adhere to professional executive salary incentive income and business performance linked to the long-term incentives and short-term incentives of professional executive and adhere to the professional executive Material incentives and spiritual incentives, efficiency first, taking into account the principle of fairness, and ultimately to achieve a win-win situation between the two sides. 


\section{REFERENCES}

[1] Longlin,"Research on the Salary Incentive Mechanism of Professional Executive in Family Enterprises Based on Systematic Thinking," Technology Square, vol. 4,2012 . (In Chinese)

[2] PangJunXu, "Incentive Mechanism of Professional Executive Based on Family Rationality," Journal of Yunnan University of Finance and Economics, vol. 4,page:12-14,2011 . (In Chinese)

[3] ShenBo,"A Study on the Growth Mechanism of China 's Tourism Professional Executive," Human Resources, vol. 12,2008. (In Chinese)

[4] WuYaLi, "Study on Spiritual Incentive Mechanism of Business," Economist, vol. 8,2005. (In Chinese)

[5] ZhuPing, "Research on the Incentive Mechanism of Employees in Private Enterprises in the Second Time," Special Economic Zone, vol. 10,2005. (In Chinese)

[6] ShiZuLiu, LiuZhiYang,"Research on the Market of Professional Executive in Private Enterprises in the Transitional Period," Fujian Forum, vol. 5,2005. (In Chinese) 